\title{
Goa e Macau: às margens do macrossistema literário de língua portuguesa
}

\section{Hélder GARMES}

Benjamin Abdala Junior publicou, em 2000, na revista Veredas, órgão da Associação Nacional de Lusitanistas, o artigo intitulado "Terra morta e outras terras: sistemas literários nacionais e o macrossistema literário da língua portuguesa", no qual

1 Hélder Garmes é professor da Faculdade de Filosofia, Letras e Ciências Humanas da USP - Universidade de São Paulo, e pesquisador do GNPq - Conselho Nacional de Desenvolvimento Científico e Tecnológico. Atua nas áreas de Literatura Portuguesa e de Estudos Comparados de Literaturas de Língua Portuguesa. Coordena dois grupos de pesquisa: Pensando Goa, registrado no Laboratório de Interlocuções com a Ásia da USP, e Grupo Eça, registrado no CNPq. Coordena o projeto temático Pensando Goa (proc. n. 2014/15657-8) financiado pela Fapesp, ao qual as reflexões do presente texto estão vinculadas; helder@usp.br 
retomava a noção de "macrossistema literário", que já aparecera em seu livro Literatura, história e política, de 1989, concebida como "um conjunto invariante abstrato", que se materializa em cada um dos sistemas literários nacionais, constituindo assim um "conjunto dialético que envolve a antiga metrópole e suas ex-colônias sem imposições e sem falácia de padrões pretensamente superiores" (ABDALA Junior, 1989, p. 18). No artigo acima referido, a noção de macrossistema literário de língua portuguesa foi retomada nos seguintes termos:

Seria um ponto de encontro dos polissistemas literários da língua portuguesa - um paradigma, logo modelo abstrato, decorrente das articulações dos sistemas literários nacionais. Esse conceito teve sua origem no desejo de se buscar uma base teórica para aproximar as literaturas de língua portuguesa, estabelecendo uma área comum de convergência dos sistemas literários nacionais. Não nos motivava apenas a busca de repertórios provenientes de raízes histórico-culturais comuns, mas também em termos prospectivos de criar bases para aproximações comunitárias, conforme tivemos oportunidade de enfatizar em várias ocasiões. Ao enfraquecimento dos Estados nacionais, parece-nos estratégico, na atualidade, relevar fatores comunitários - uma forma de se contrapor à estandartização dos produtos culturais ligados aos processos de mundialização da economia capitalista. (Abdala Junior, 2000, p. 527)

Poder-se-ia contestar a referida proposição da existência de um macrossistema literário de língua portuguesa, argumentando que ele só se aplicaria a Portugal e ao Brasil, já que não são 
consensuais a existência e consolidação de sistemas literários nacionais nos países africanos de língua oficial portuguesa e muito menos no Timor Leste. Também poderia ser contestada a ideia prospectiva de que uma comunidade linguística supranacional em língua portuguesa propiciaria uma forma de resistência à estandartização dos produtos culturais em escala global, uma vez que, também nesse contexto periférico, sempre há a busca de poder hegemônico de uma parte sobre a outra, reproduzindo em menor escala o que acontece no plano global - como ocorre, por exemplo, na relação do Brasil com o Mercosul, no âmbito, sobretudo, da política e da economia.

No entanto, tais possíveis críticas não desqualificam aquilo que há de mais profícuo na proposição de Benjamin Abdala Junior: a ideia de que o compartilhamento da língua portuguesa em diversas partes do mundo criou certos vínculos históricos e culturais. Tais vínculos não gerariam necessariamente a Comunidade dos Países de Língua Portuguesa que hoje conhecemos sem que a vontade política desses países assim o quisesse. Por razões diversas, questiona-se hoje o sentido e valor dessa comunidade, mas, ainda que amanhã venha a se extinguir, as consequências desses vínculos não serão facilmente apagadas e continuarão a merecer atenção, já que nesse processo houve, em graus e contextos muitos distintos, o vínculo entre literatura e sociedade, entre língua e cultura.

A sobreposição entre língua e cultura não se faz sem diversos graus de complexidade, notadamente quando tomada da perspectiva dos estudos da cultura. Em seu livro A idéia de cultura (2005, p. 52), Terry Eagleton contesta Raymond Williams, que definia cultura por meio de sua sobreposição com o campo de influência de uma língua. Eagleton nota que a língua inglesa, por exemplo, abarca diversas culturas distintas. 
Se é verdade que podemos facilmente identificar várias culturas empregando uma mesma língua, como é o caso do português, é do mesmo modo verdade que, quando uma cultura nacional traz em seu interior várias línguas (como é o caso exemplar da Índia, que possui centenas de línguas), essa cultura nacional compartilha de distintas matrizes culturais. Vale lembrar que o Brasil, apesar de sempre caracterizado como país de uso exclusivo da língua portuguesa, está nessa última categoria, pois conta com a existência das diversas línguas e culturas indígenas. Mesmo Portugal não estaria livre dessa diversidade, se lembrarmos os chamados dialetos guadramilês, rionorês, mirandês e barranquenho.

Estabelecendo uma diversificada gradação de relações, língua e cultura se sobrepõem em diversos aspectos. É quase impossível dissociar completamente uma coisa e outra, ainda quando, por razões históricas, essa relação torna-se muito tênue, como é o caso, por exemplo, do crioulo de Korlai, da costa oeste indiana, cujo povo, além da cristandade, quase nada guarda culturalmente da presença portuguesa naquela região.

Observado dessa perspectiva, o chamado "mundo de língua portuguesa" convive cotidianamente com outras línguas e culturas, sobretudo no antigo espaço colonial: quer no Brasil, quer nos países africanos ou outras partes do globo que sofreram dominação lusitana. Não há como conceber um virtual macrossistema literário de língua portuguesa como um bloco uníssono e coerente. Deve-se tomá-lo em conexão com todas essas outras línguas e culturas, o que acaba se revelando uma tarefa bastante complexa, que só pode se realizar fragmentária e gradualmente.

Faz-se necessário, entretanto, observar que, ao tratarmos de literatura - objeto de nosso interesse - e não de oratura -, estamos lidando com a língua em sua forma escrita. Isso apresenta especificidades, pois sempre nos referimos a uma parcela da 
população desses países que têm acesso a essa forma. Em todos os países de língua oficial portuguesa, há um número, maior ou menor, de indivíduos que não têm acesso à língua escrita. É certo que, em alguns casos, a imensa maioria compartilha desse acesso e, em outros, apenas uma pequena minoria, e isso faz muita diferença na configuração do que se pode designar por cultura nacional letrada de língua portuguesa em cada uma dessas localidades. De qualquer modo, todas as nações que adotaram o português como língua oficial têm hoje uma produção letrada de maior ou menor significação para os membros daquelas comunidades nacionais.

Há, entretanto, casos em que a língua portuguesa foi minoritária culturalmente e que jamais chegaram a constituir nações independentes de língua oficial portuguesa. Ainda assim, geraram uma produção escrita significativa durante séculos e que, após o final do período de dominação lusitana, entraram em franco recuo. Goa e Macau são exemplares nesse aspecto e é sobre tais casos que pretendemos nos deter, pois também a produção literária dessas localidades, em nosso entendimento, pode fazer parte do macrossistema literário de língua portuguesa.

Como é sabido, ambas as localidades foram ocupadas pelos portugueses no século XVI. Goa venceu o jugo lusitano em 19 de dezembro de 1961 e passou a fazer parte do Estado da Índia. Macau deixou de ser território português em 20 de dezembro de 1999, tornando-se uma região administrativa especial da China. Entendemos que refletir sobre essa produção tendo no horizonte o macrossistema literário de língua portuguesa é uma das maneiras mais propositivas de lê-la, já que poderemos retirá-la de seu encapsulamento.

Se é verdade que o trabalho de entender essa produção a partir de seu local de enunciação - Goa e Macau - encontra-se ain- 
da muito incipiente, e temos, com muitos colegas, tentado cerrar fileiras para a concretização dessa tarefa, um outro passo tão importante quanto esse para o entendimento e valorização dessa produção é definir seu lugar, ainda que periférico, no âmbito das literaturas de língua portuguesa.

Sabemos o quanto os países africanos de língua oficial portuguesa têm trabalhado no sentido de se afirmar no cenário literário. Hoje podemos encontrar facilmente nas livrarias brasileiras Mia Couto, Pepetela, Luandino Vieira, Ondjaki, o que há dez anos só ocorreria em Portugal. Esse fenômeno, além da parcela que podemos atribuir ao mercado de livros, se deve a um trabalho bastante denso e arguto de professores universitários brasileiros, que criaram áreas de estudos, centros, departamentos, com o intuito de institucionalizar a literatura de língua portuguesa produzida na África, tratando-a como necessária para a formação do aluno brasileiro. No artigo supracitado, por exemplo, Abdala Junior, ao tratar de Terra morta (1949), de Castro Soromenho, estabelece conexões desse romance com Gaibéus (1939), de Alves Redol, e com a obra de Jorge Amado, assim como com O segredo da morta (1935), de Assis Junior, e com todo o movimento dos Novos Intelectuais de Angola, empenhados na constituição de uma literatura angolana. Vincula, assim, literatura angolana, portuguesa e brasileira, permitindo vislumbrar o que designa de macrossistema literário de língua portuguesa.

A tradição literária africana de língua portuguesa, fosse qual fosse, até recentemente estava marginalizada do processo de formação institucional do leitor brasileiro, que considerava apenas as tradições literárias brasileira e europeia - e alguma coisa da latino-americana. A pressão dos movimentos negro e indígena acabou culminando na Lei n. 11.645/08, de 10 de março de 2008, que instituiu a obrigatoriedade do ensino de "história e 
cultura afro-brasileira e indígena" no ensino fundamental de nossas escolas. Isso possibilitou a valorização das literaturas de língua portuguesa da África, assim como a valorização das culturas e línguas indígenas brasileiras. Consequentemente, o mercado de livros passou a atender também esse novo filão.

É evidente que, em relação à literatura de língua portuguesa produzida em Goa e em Macau, não podemos contar com esse gênero de engajamento social que venha a incluir, algum dia, tais literaturas no currículo escolar brasileiro, português, angolano ou de qualquer outra nação da Comunidade dos Países de Língua Portuguesa. No entanto, temos, no repertório que foi deixado no decorrer de quase cinco séculos, um conjunto de textos que pode contribuir para o entendimento de como literaturas assumidamente periféricas se constituíram às margens de sistemas nacionais. Propicia ainda o estudo, no caso específico de Goa e de Macau, de como aquilo que se convencionou chamar de Oriente e de Ocidente ganhou centralidade constitutiva nessas literaturas, isto é, como tais literaturas se conceberam enquanto expressão dessa tensão entre polos geográficos distintos, que, tal qual postula Edward W. Said (2001), são de fato a forma como designamos a experiência histórica do colonialismo europeu, sobretudo desde o final do século XVIII, tomados aqui no âmbito das literaturas de língua portuguesa. Até o século XVIII, a oposição que vigorava era entre cristãos e "hereges".

Assim, no corpo de textos que hoje constitui a literatura de língua portuguesa de Goa e de Macau, podemos identificar ao menos dois grandes conjuntos de obras: textos publicados antes e depois do século XIX. Até o advento do liberalismo em Portugal, a imprensa de Goa funcionou com alguma regularidade nos séculos XVI e XVII, perdendo força no século XVIII, enquanto a de Macau manteve-se ativa ainda nesse século, até a sua proi- 
bição, por parte do Marquês de Pombal. A primeira imprensa enviada para o espaço colonial foi instalada em Goa em 1556, no Colégio de São Paulo, estampando naquele mesmo ano as Conclusiones philosophicae, tese defendida pelo jesuíta Francisco Cabral. Em Macau, a primeira publicação data de 1588 e intitula-se Christiani Pueri Institutio, do padre Juan Bonifácio de Salamanca (MAtos, 1991-1992, p. 156). Dominada pela Igreja de Roma, a imprensa desses primeiros séculos foi eminentemente católica e, em grande parte, em latim, como é de conhecimento de todos.

A imprensa laica ocorre de fato após o advento do liberalismo. Com o retorno do D. João VI a Portugal em 1821 e a assinatura da Carta Constitucional em 1 de outubro de 1822, Goa e Macau se viram em condições de importar máquinas impressoras e assim teve início a produção do segundo conjunto significativo de textos dessas duas localidades. Os goeses, antecipando-se à assinatura da Carta, trouxeram de Bombaim uma máquina impressora já em 1821, saindo o primeiro número da Gazeta de Goa em 22 de dezembro daquele ano. Macau também se antecipou à assinatura da Carta, sendo o primeiro número do periódico Abelha da China publicado em 12 de setembro de 1822. A partir daí, temos nesses dois espaços de domínio português uma imprensa muito mais dinâmica e volumosa do que aquela promovida pelas missões católicas em séculos anteriores (cf. GARMes, 2004, p. 15-86).

Nesse segundo conjunto de obras, que recobrem os séculos XIX e XX, adentrando ao XXI, faz-se necessário assinalar uma relevante distinção entre a produção de Goa e a de Macau. Enquanto Goa deixa de ser território português em 1961, fazendo com que a produção literária em língua portuguesa sofresse um profundo corte, Macau manteve-se sob domínio português até 
1999, mesmo depois da independência das colônias africanas e do Timor Leste, ocorridas entre 1975 e 1976. A assinatura da Declaração Conjunta do Governo da República Portuguesa e do Governo da República Popular da China sobre a Questão de Macau, de 13 de abril de 1987, que previa o término da administração portuguesa em 20 de dezembro de 1999, acabou por promover, por parte do governo português, uma série de iniciativas que resultaram no estímulo à produção literária de língua portuguesa em Macau, fazendo com que seu escopo literário fosse significativamente ampliado nos últimos anos daquela administração.

Portanto, temos na dinâmica literária em língua portuguesa dessas duas localidades aspectos muito semelhantes, mas também muito distintos. Apenas para citar os trabalhos mais recentes, as especificidades da produção de Macau foram investigadas, por exemplo, por Mônica Simas. Em Margens do destino - Macau e a Literatura de Língua Portuguesa, de 2007, fazendo intersecções com outras literaturas em nossa língua, Simas revela-nos a dinâmica da produção literária de e sobre Macau, de uma perspectiva sobretudo interna, demonstrando o quanto, aos poucos, se desenvolveu ali uma memória do território, assim como um "olhar intérprete", que busca as especificidades daquela cultura. As particularidades da produção de Goa podem ser identificadas, por exemplo, no trabalho de Eufeminano de Jesus Miranda, Oriente e Ocidente na literatura goesa: realidade, ficção, história e imaginação (2012), que reconstitui historicamente aquela tradição de textos literários e procura apontar o que possui de mais específico. Esses dois exemplos demonstram a existência de trabalhos importantes que conseguiram localizar, sistematizar e apresentar interpretações para a dinâmica sobretudo interna dessas literaturas e já delinear algumas de suas relações com o universo literário de língua portuguesa. 
À parte o trabalho de continuidade no aprofundamento do conhecimento de tais especificidades, e contribuindo nesse sentido, faz-se necessário colocá-las mais substancialmente no âmbito do macrossistema literário de língua portuguesa, espaço privilegiado, em nosso entendimento, para evidenciar aquilo que lhes é mais peculiar: seus traços locais. Além dos acima referidos, alguns estudos pontuais e de fôlego já foram realizados nessa perspectiva. No caso de Goa, que é de nosso maior conhecimento, além dos estudos já considerados "clássicos", como os de Filinto Cristo Dias (1963) e Vimala Devi e Manuel de Seabra (1971), podemos lembrar o trabalho de Ana Cristina Kerbauy (2008), que elabora um estudo comparativo entre duas revistas literárias do período do Romantismo: a Ilustração Goana (1864-1866) e a Minerva Brasiliense (1843-1845), abordando as diferentes concepções da relação entre literatura, sociedade e autonomia intelectual que cada uma daquelas publicações apresentava em relação aos contextos nos quais emergiram, concluindo que, tanto no Brasil, ex-colônia de Portugal, quanto na então colônia indiana portuguesa, o processo colonial gerou uma série de contradições que obrigou os emergentes campos de produção erudita a se constituírem sob forte e diversificada ambivalência.

Já o trabalho de João Cunha (2010) aproxima a literatura goesa de língua portuguesa da sua matriz colonial, realizando um estudo comparativo entre o romance Jacob e Dulce: cenas da vida indiana (1896), do goês Francisco João da Costa, e o conjunto da obra de Eça de Queirós, envolvendo ainda uma crítica ao romance elaborada pelo brasileiro Visconde de Taunay e publicada na Revista Brasileira em 1897, revelando dimensões insuspeitas das relações literárias entre Portugal, Brasil e Goa.

Se Everton Machado (2006) demonstrou o quanto o romance Os brahamanes (1866), do goês Francisco Luís Gomes, 
estabelecia uma relação intertextual não somente com a literatura portuguesa, mas também com o romantismo europeu em geral, sobretudo com o francês, em trabalho recente, de 2011, tive a oportunidade de analisar os sentidos da apropriação que o mesmo romance fazia de um dos postulados mais caros ao imaginário colonialista português: a ideia de mestiçagem. Em estudo comparativo (2011) entre o romance de Francisco Luís Gomes e $O$ guarani (1857), de José de Alencar, procurei demonstrar o quanto o imaginário português em torno da mestiçagem, tomada como solução simbólica para o conflito colonial, informa ambos os romances, cumprindo papel muito distinto em cada um deles, por conta dos sentidos que ganha em cada uma dessas localidades.

No caso de Macau, ainda não pude ler investigações pontuais e de fôlego dessa natureza no âmbito da literatura comparada. Além daquele de Mônica Simas, o único trabalho de que tive notícia é de autoria de Wang Suo Ying (1996) e diz respeito à comparação de Amor de perdição (1862), de Camilo Castelo Branco, com o romance $O$ sonho do pavilhão vermelho, de Cao Xueqin, escrito em meados do século XVIII, confrontando, portanto, um texto em português com um texto originalmente escrito em mandarim. Evidentemente trabalhos dessa natureza são muito importantes, uma vez que a literatura comparada não se encontra subordinada à língua original do texto literário. Tratando de comunidades que conviveram e convivem com mais de uma língua, como é o caso de Goa e de Macau, é mesmo fundamental estudar o quanto as tradições literárias das línguas empregadas nessas localidades se encontram entrelaçadas. Todavia, essa é uma outra tarefa.

Quanto ao macrossistema de literaturas de língua portuguesa, vale ainda lembrar uma abordagem muito produtiva a ser adotada: comparar a literatura de Goa com a de Macau, uma 
vez que ambas são forjadas na tensão Ocidente/Oriente, como foi anteriormente observado. Como essa tensão é peculiarmente configurada em cada uma dessas tradições é algo que ainda está para ser descrito e analisado.

No contexto das literaturas de língua portuguesa, as de Goa e de Macau constituem um paradigma diferenciado por serem pouco afeitas ao "instinto de nacionalidade", para empregar a expressão de Machado de Assis (1873/1959, p. 28). São literaturas caracterizadas por aspectos regionais, moldadas, como foi observado, pela tensão entre cristãos e "hereges", entre Ocidente e Oriente, e conectadas de formas diversas com o virtual macrossistema literário de língua portuguesa. Nunca tendo sido a língua hegemônica dessas sociedades, o português promove a constituição de um meio literário bastante entrelaçado às línguas dominantes nessas localidades, como o cantonês e o mandarim em Macau e o concani e o marathi em Goa. Além disso, a produção literária de língua inglesa surge como uma referência importante para essas duas comunidades, por conta da zona de influência de Hong Kong na China e da colonização inglesa na Índia.

Ao propor um esforço mais acentuado e sistemático de leituras comparativas entre as literaturas de Goa e de Macau e as outras literaturas do macrossistema literário de língua portuguesa, nosso intuito é tanto buscar um sentido mais amplo e denso para os textos produzidos naquelas localidades, quanto reconfigurar, a partir da inserção desse novo paradigma, aquilo que já foi escrito sobre a dinâmica das literaturas de língua portuguesa no mundo, redimensionado essa história a partir de suas margens.

Vale finalmente observar que estudar tais literaturas não significa atribuir positividade ao colonialismo português, como já ocorreu no passado, quando A literatura indo-portuguesa, de Vimala Devi e Manuel de Seabra (1971) serviu aos interesses da ditadura 
portuguesa, na busca de demonstrar a suposta portugalidade de Goa. Ainda que marcada muitas vezes pelo ponto de vista do colonizador, é possível estudar de forma crítica essa produção literária, pois apresenta conflitos, contradições e impasses que desafiam o leitor mais perspicaz. O importante é não perder de vista o contexto de enunciação desses textos, que é complexo, contraditório, dinâmico, e no qual sempre vigora a exploração colonial. Ali, velhas formas literárias ganham novos sentidos, novas formas são criadas e, sobretudo, são colocados, ao pesquisador, problemas relativos ao conjunto de valores que se defende quando se procura definir os textos canônicos dessas literaturas, demonstrando que não há como falar de qualidade literária sem que isso envolva referências éticas, políticas, sociais e culturais.

\section{Referências}

Abdala Junior, Benjamin. Terra morta e outras terras: sistemas literários nacionais e o macrossistema literário da língua portuguesa. Revista Veredas, Porto, v. 3-II, Porto, 2000, p. 523-536, 2000.

. Literatura, história e política: literaturas de língua portuguesa no século XX. São Paulo: Ática, 1989.

Alencar, José de. O guarani. Rio Grande: Tipografia do Diário, 1857.

Assis, Machado de. Instinto de nacionalidade. Machado de Assis: crítica, notícia da atual literatura brasileira. São Paulo: Agir, 1959. p. 28-34. Primeira edição publicada em 1873.

Costa, Francisco João da. Jacob e Dulce: cenas da vida indiana. Margão: Tipografia do Ultramar, 1896. 
Gunha, João Figueiredo Alves da. Uma leitura crítica de Jacó e Dulce: cenas da vida indiana à luz do realismo de Eça de Queirós. 2010. Dissertação (Mestrado em Literatura Portuguesa) Faculdade de Filosofia, Letras e Ciências Humanas, Universidade de São Paulo, São Paulo, 2010. 2 v.

Dias, Filinto Cristo. Esboço da história da literatura indo-portuguesa. Bastorá, Goa: Tipografia Rangel, 1963.

Eagleton, Terry. A idéia de cultura. Tradução de Sandra Castello Branco. São Paulo: Editora Unesp, 2005.

GARMes, Hélder. Ímpar entre pares - personagens mestiças e mestiçagem nos romances O guarani e Os brahamanes. 2011. Tese (Livre-docência em Literatura Portuguesa) - Faculdade de Filosofia, Letras e Ciências Humanas, Universidade de São Paulo, São Paulo, 2011.

. Origem e estabelecimento da imprensa e da literatura de Goa. In: Garmes, Hélder (Org.). Oriente, engenho e arte: imprensa e literatura de língua portuguesa em Goa, Macau e Timor Leste. São Paulo: Alameda, 2004. p. 15-86.

Gomes, Francisco Luís. Os brahamanes. Lisboa: Typ. da Gazeta de Portugal, 1866.

Kerbauy, Ana Cristina. Ilustração Goana e Minerva Brasiliense: a sedimentação do romantismo em Goa e no Brasil. 2008. Dissertação (Mestrado em Literatura Portuguesa) - Faculdade de Filosofia, Letras e Ciências Humanas, Universidade de São Paulo, São Paulo, 2008.

LeI n. 11.645/08, de 10 de março de 2008. Disponível em: <http://www.planalto.gov.br/ccivil_03/_ato2007-2010/2008/lei/11 1645. 
htm>. Acesso em: 10 jul. 2017.

Machado, Everton. Christianisme, castes et colonialisme dans le roman Les brahmanes (1866) du goannais Francisco Luis Gomes (1829-1869). 2006. Tese (Doutorado em Literatura Comparada) - Université Paris IV, Paris, e Universidade de São Paulo, São Paulo, 2006.

Matos, Manuel Cadafaz de. A tipografia quinhentista de expressão cultural portuguesa no oriente veículo de propagação dos ideais humanísticos (no quarto centenário da introdução da imprensa jesuítica no Japão). Revista Humanitas, Coimbra, n. 43-44, p. 153-171, 1991-1992.

Miranda, Eufeminiano de Jesus. Oriente e Ocidente na literatura goesa: realidade, ficção, história e imaginação. Bardez: Goa 1556, 2012.

SAID, Edward W. Orientalismo. Tradução de Tomás Rosa Bueno. São Paulo: Companhia das Letras, 2001.

SEAbra, Manuel; Devi, Vimala. A literatura indo-portuguesa. Lisboa: Junta de Investigações do Ultramar, 1971. 2 v.

Simas, Mônica. Margens do Destino: Macau e a Literatura de Língua Portuguesa. São Caetano do Sul: Yendis, 2007.

YING, Wang Suo. Estudo comparado sobre duas tragédias amorosas: O sonho do pavilhão vermelho e Amor de perdição. Macau: Instituto Cultural de Macau, 1996.

GARMES, Hélder. Goa e Macau: às margens do macrossistema literário de língua portuguesa. In: Simas, Monica (Org.). Estudos sobre Macau e outros orientes. São Paulo: Paulistana, 2017. p. 169-183. 